\title{
Function Generation Synthesis with a 2-DoF Overconstrained Double-Spherical 7R Mechanism Using the Method of Decomposition and Least Squares Approximation
}

\author{
G. Kiper ${ }^{1}$, B. Bağdadioğlu ${ }^{2}$ \\ ${ }^{1}$ İmir Institute of Technology,Turkey,e-mail: gokhankiper@iyte.edu.tr \\ ${ }^{2}$ Izmir Institute of Technology, Turkey,e-mail: barisbagdadioglu@iyte.edu.tr
}

\begin{abstract}
This study addresses the approximate function generation synthesis with an overconstrained two degrees-of-freedom double spherical $7 \mathrm{R}$ mechanism using least squares approximation with equal spacing of the design points on the input domain. The $7 \mathrm{R}$ mechanism is a constructed by combining a spherical $5 \mathrm{R}$ mechanism with a spherical $4 \mathrm{R}$ mechanism with distant centers and a common moving link and then removing the common link. This construction allows the analysis and synthesis of the resulting single-loop mechanism by decomposing it into fictitious $5 \mathrm{R}$ and $4 \mathrm{R}$ loops. The two inputs to the mechanism are provided in the $5 \mathrm{R}$ loop and the output is in the $4 \mathrm{R}$ loop. The fictitious output of the $5 \mathrm{R}$ loop is an input to the $4 \mathrm{R}$ loop this intermediate variable is used to also decompose the function to be generated. This decomposition provides the designer extra freedom in synthesis and enables decreasing the error of approximation. A case study is presented at the end of the study where the $7 \mathrm{R}$ design is compared with an equivalent spherical $5 \mathrm{R}$ mechanism; hence the advantage of the $7 \mathrm{R}$ mechanism is demonstrated.
\end{abstract}

Key words: Multi-input function generation, overconstrained mechanism, method of decomposition, least squares approximation.

\section{Introduction}

Due to constructional simplicity, low cost, ease of use and stiffness capabilities, kinematically deficient manipulators are becoming popular ([1] and as an example see [2]). Some researchers use the deficient term as a substitute to under-actuated, however what we mean by a deficient manipulator is a manipulator with less degrees-of-freedom (dof) than the task-space dimension. Although analytical synthesis methods for single dof mechanisms are widely studied $[3,4]$, mostly optimization methods are utilized for determining link length dimensions of multi-dof 
mechanisms (ex. see [5]). An exceptional study is analytical motion synthesis of a 3-RPS manipulator [6].

We have recently presented several studies on synthesis of 2-dof spherical and planar $5 \mathrm{R}$ mechanisms $[7,8,9]$ as a case study of approximate analytical synthesis of multi-dof mechanisms. Specifically in [7] the function synthesis problem for a spherical 5R mechanism is addressed, where one of the fixed joints is an input, the mid-joint is the second input and the remaining fixed joint is the output. The reason of choosing the mid-joint as an input instead of a joint adjacent to a fixed joint is that this selection leads to linear set of equations. We make use of such a spherical 5R loop in this study, as well.

Another tool to enhance the stiffness of a manipulator is overconstraint. Huang et al. [1] note that most of the lower-mobility (deficient) parallel manipulators are overconstrained mechanisms. Recently we worked on the Bennett $6 \mathrm{R}$ mechanisms $[10,11]$. The Bennett $6 \mathrm{R}$ mechanisms are the single-loop double-planar, doublespherical and plano-spherical linkages, which are respectively obtained by combining two planar slider-crank mechanisms with intersecting planes, two spherical four bar linkages with distinct centers and a planar four-bar and a spherical fourbar mechanisms, all with a common moving link connected to the common fixed link, and then removing the redundant joint connecting the two common links [12]. The removed joint is called a passive joint. Since the dof of these mechanisms according to Grübler-Kutzbach mobility formula is equal to zero despite the single dof mobility of the mechanisms, the mechanisms are overconstrained with general constraint one [13]. In [10] we derived the input-output equations of the Bennett 6R mechanisms and in [11] we worked out the function synthesis of these linkages making use of the method of decomposition [14]. The method of decomposition is based on the fact that the above-mentioned single loop 6R mechanisms may be decomposed into two imaginary loops. By taking the input and output joints as the fixed joints, the $\mathrm{I} / \mathrm{O}$ equations for each imaginary loop are obtained. The passive joint is output for the first loop and input for the second loop. Besides being overconstrained, these linkages prove themselves useful in synthesis thanks to the large number of construction parameters (link lengths) [11].

In this study we combine a 2-dof 5R spherical mechanism with a single-dof $4 \mathrm{R}$ spherical mechanism with a common moving link and remove the redundant common joint to obtain a single-loop 2-dof overconstrained 7R spherical mechanism. We address the problem of function synthesis of this mechanism for approximate generation of a continuous function with two inputs and single output. For the synthesis method we use the least squares approximation method instead of the Chebyshev method used in [7]. 


\section{The Double-Spherical 7R Mechanism}

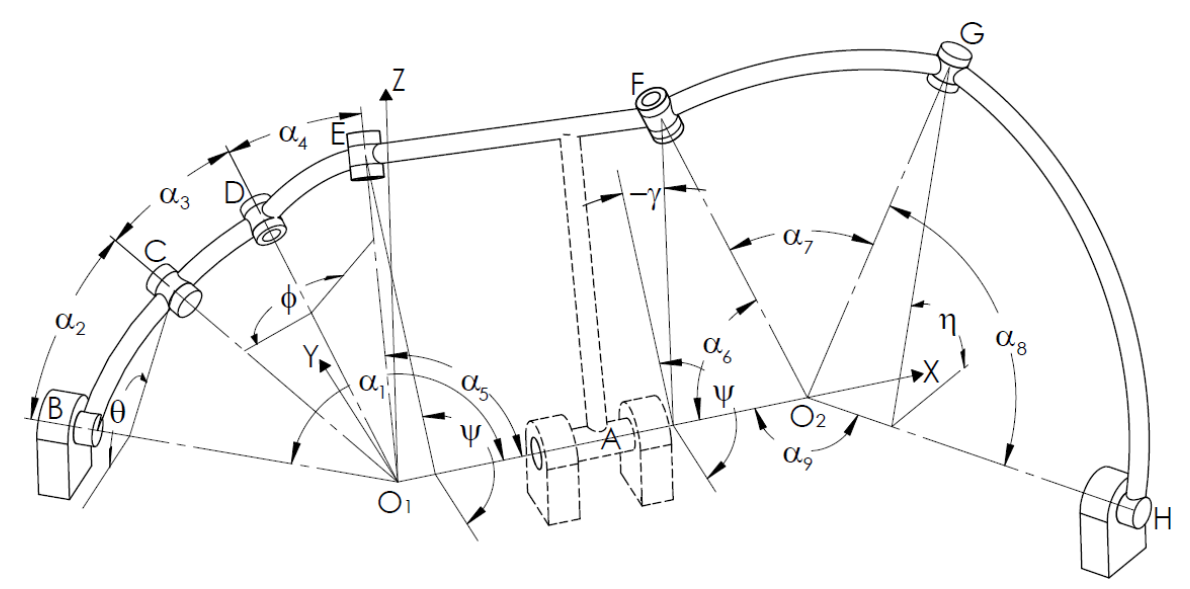

Fig. 1 Double-spherical 7R mechanism

The double spherical $7 \mathrm{R}$ mechanism in Fig. 1 is constructed by combining the spherical 5-bar ABCDE and the spherical 4-bar AFGH and then removing the common joint $A$. The inputs of the mechanism are the angles $\theta$ and $\phi$ in the fictitious 5-bar and the output is the angle $\eta$ associated to link 8. In applying the method of decomposition, the output $\psi$ of the 5-bar is treated as the input to the 4bar. Notice that since we are dealing with a function synthesis problem, without loss of generality the radii of the spheres can be taken as 1 . The construction parameters are the spherical link lengths $\alpha_{1}, \ldots, \alpha_{9}$ and the twist angle $\gamma$. To simplify the formulation let us assume $\gamma=0$. See [11] for the general case.

We start by deriving the input/output (I/O) relationship for the loops. Coordinates of $\mathrm{B}, \mathrm{C}$ and $\mathrm{E}$ :

$$
\overline{\mathrm{C}}=\mathrm{Z}\left(\alpha_{1}\right) \mathrm{X}(\theta) \mathrm{Z}\left(\alpha_{2}\right)\left[\begin{array}{l}
1 \\
0 \\
0
\end{array}\right]=\left[\begin{array}{c}
\mathrm{c}_{1} \mathrm{c}_{2}-\mathrm{s}_{1} \mathrm{~s}_{2} \mathrm{c} \theta \\
\mathrm{s}_{1} \mathrm{c}_{2}+\mathrm{c}_{1} \mathrm{~s}_{2} \mathrm{c} \theta \\
\mathrm{s}_{2} \mathrm{~s} \theta
\end{array}\right], \overline{\mathrm{E}}=\mathrm{X}(-\psi) \mathrm{Z}\left(-\alpha_{5}\right)\left[\begin{array}{l}
1 \\
0 \\
0
\end{array}\right]=\left[\begin{array}{c}
\mathrm{c}_{5} \\
-\mathrm{s}_{5} \mathrm{c} \psi \\
\mathrm{s}_{5} \mathrm{~s} \psi
\end{array}\right]
$$

where $\mathrm{X}($.) and $\mathrm{Z}($.$) are 3 \times 3$ rotation matrices about $\mathrm{x}$ - and $\mathrm{z}$-axes, respectively, $c_{k}=\cos \alpha_{k}, s_{k}=\sin \alpha_{k}, c \theta=\cos \theta$, etc. Let $C E=\beta . \beta$ depends on $\alpha_{3}, \alpha_{4}$ and the joint variable $\phi$ via the spherical cosine theorem for triangle $\mathrm{CDE}$ :

$$
\mathrm{c}_{3} \mathrm{c}_{4}+\mathrm{s}_{3} \mathrm{~s}_{4} \mathrm{c} \phi=\mathrm{c} \beta
$$


On the other hand the scalar product of $\overline{\mathrm{C}}$ and $\overline{\mathrm{E}}$ from Eq. (1) yields

$$
\overline{\mathrm{C}} \cdot \overline{\mathrm{E}}=\mathrm{c} \beta \Rightarrow \mathrm{c}_{1} \mathrm{c}_{2} \mathrm{c}_{5}-\mathrm{s}_{1} \mathrm{~s}_{2} \mathrm{c}_{5} \mathrm{c} \theta-\mathrm{s}_{1} \mathrm{c}_{2} \mathrm{~s}_{5} \mathrm{c} \psi-\mathrm{c}_{1} \mathrm{~s}_{2} \mathrm{~s}_{5} \mathrm{c} \theta \mathrm{c} \psi+\mathrm{s}_{2} \mathrm{~s} \theta \mathrm{s}_{5} \mathrm{~s} \psi=\mathrm{c} \beta
$$

Combining Eqs. (2)-(3) and rearranging

$$
\mathrm{c}_{1} \mathrm{c}_{2} \mathrm{c}_{5}-\mathrm{c}_{3} \mathrm{c}_{4}-\mathrm{s}_{3} \mathrm{~s}_{4} \mathrm{c} \phi-\mathrm{s}_{1} \mathrm{~s}_{2} \mathrm{c}_{5} \mathrm{c} \theta+\mathrm{s}_{2} \mathrm{~s}_{5} \mathrm{~s} \theta \mathrm{s} \psi-\mathrm{c}_{1} \mathrm{~s}_{2} \mathrm{~s}_{5} \mathrm{c} \theta \mathrm{c} \psi-\mathrm{s}_{1} \mathrm{c}_{2} \mathrm{~s}_{5} \mathrm{c} \psi=0
$$

Eq. (4) can be written in the following polynomial form

$$
\sum_{j=1}^{m} P_{j} f_{j}(\mathbf{x})-F(\mathbf{x})=0
$$

where $\mathrm{m}=5, \mathbf{x}=\{\theta, \phi, \psi\}$ and

$$
\mathrm{P}_{1}=\frac{\mathrm{c}_{1} \mathrm{c}_{2} \mathrm{c}_{5}-\mathrm{c}_{3} \mathrm{c}_{4}}{\mathrm{~s}_{1} \mathrm{c}_{2} \mathrm{~s}_{5}}, \mathrm{P}_{2}=\frac{\mathrm{s}_{3} \mathrm{~s}_{4}}{\mathrm{~s}_{1} \mathrm{c}_{2} \mathrm{~s}_{5}}, \mathrm{P}_{3}=\frac{\mathrm{t}_{2}}{\mathrm{t}_{5}}, \mathrm{P}_{4}=\frac{\mathrm{t}_{2}}{\mathrm{~s}_{1}}, \mathrm{P}_{5}=\frac{\mathrm{t}_{2}}{\mathrm{t}_{1}}
$$

$\mathrm{f}_{1}(\mathbf{x})=1, \mathrm{f}_{2}(\mathbf{x})=-\mathrm{c} \phi, \mathrm{f}_{3}(\mathbf{x})=-\mathrm{c} \theta, \mathrm{f}_{4}(\mathbf{x})=\mathrm{s} \theta \mathrm{s} \psi, \mathrm{f}_{5}(\mathbf{x})=-\mathrm{c} \theta \mathrm{c} \psi$ and $\mathrm{F}(\mathbf{x})=\mathrm{c} \psi$

for $t_{k}=\tan \alpha_{k} . P_{j}$ are determined using least squares approximation as explained in Section 3. After $P_{j}$ are determined, the construction parameters of the mechanism are determined from Eq. (6) as

$$
\alpha_{1}= \pm \cos ^{-1} \frac{P_{5}}{P_{4}}, \alpha_{2}=\tan ^{-1}\left(P_{4} s_{1}\right), \alpha_{5}=\tan ^{-1} \frac{t_{2}}{P_{3}}, \alpha_{3}=\frac{A \pm B}{2}, \alpha_{4}=\frac{A \mp B}{2}
$$

where $A=\cos ^{-1}\left[c_{2}\left(c_{1} c_{5}-\left(P_{1}+P_{2}\right) s_{1} s_{5}\right)\right], B=\cos ^{-1}\left[c_{2}\left(c_{1} c_{5}-\left(P_{1}-P_{2}\right) s_{1} s_{5}\right)\right]$. Notice from Fig. 1 and Eq. (2) that interchanging $\alpha_{3}$ and $\alpha_{4}$ does not affect the I/O relationship. For the spherical 4-bar AFGH, the coordinates of joints $F$ and $G$ are

$$
\overline{\mathrm{F}}=\mathrm{X}(-\psi) \mathrm{Z}\left(\alpha_{6}\right)\left[\begin{array}{c}
-1 \\
0 \\
0
\end{array}\right]=\left[\begin{array}{c}
-\mathrm{c}_{6} \\
-\mathrm{s}_{6} \mathrm{c} \psi \\
\mathrm{s}_{6} \mathrm{~s} \psi
\end{array}\right], \overline{\mathrm{G}}=\mathrm{Z}\left(\alpha_{9}\right) \mathrm{X}(-\eta) \mathrm{Z}\left(\alpha_{8}\right)\left[\begin{array}{c}
-1 \\
0 \\
0
\end{array}\right]=-\left[\begin{array}{c}
\mathrm{c}_{8} \mathrm{c}_{9}-\mathrm{s}_{8} \mathrm{~s}_{9} \mathrm{c} \eta \\
\mathrm{c}_{8} \mathrm{~s}_{9}+\mathrm{s}_{8} \mathrm{c}_{9} \mathrm{c} \eta \\
-\mathrm{s}_{8} \mathrm{~s} \eta
\end{array}\right]
$$

Evaluating the scalar product of $\overline{\mathrm{F}}$ and $\overline{\mathrm{G}}$ and manipulating:

$$
\mathrm{c}_{6} \mathrm{c}_{8} \mathrm{c}_{9}-\mathrm{c}_{7}+\mathrm{s}_{6} \mathrm{c}_{8} \mathrm{~s}_{9} \mathrm{c} \psi+\mathrm{s}_{6} \mathrm{~s}_{8} \mathrm{c}_{9} \mathrm{c} \eta \mathrm{c} \psi+\mathrm{s}_{6} \mathrm{~s}_{8} \mathrm{~s} \eta \mathrm{s} \psi-\mathrm{c}_{6} \mathrm{~s}_{8} \mathrm{~s}_{9} \mathrm{c} \eta=0
$$

Eq. (9) can be written in polynomial form of Eq. (5), but $m=4, \mathbf{x}=\{\psi, \eta\}$ and 


$$
\begin{gathered}
P_{1}=\frac{c_{6} c_{8} c_{9}-c_{7}}{c_{6} s_{8} s_{9}}, P_{2}=\frac{t_{6}}{t_{8}}, P_{3}=\frac{t_{6}}{t_{9}}, P_{4}=\frac{t_{6}}{s_{9}}, \\
f_{1}(x)=1, f_{2}(x)=c \psi, f_{3}(x)=c \eta c \psi, f_{4}(x)=s \eta s \psi \text { and } F(x)=c \eta
\end{gathered}
$$

After $\mathrm{P}_{\mathrm{j}}$ are determined as explained in Section 3, the construction parameters are determined from Eq. (10) as

$$
\alpha_{9}= \pm \cos ^{-1} \frac{\mathrm{P}_{3}}{\mathrm{P}_{4}}, \alpha_{6}=\tan ^{-1}\left(\mathrm{P}_{4} \mathrm{~s}_{9}\right), \alpha_{8}=\tan ^{-1} \frac{\mathrm{t}_{6}}{\mathrm{P}_{2}}, \alpha_{7}= \pm \cos ^{-1}\left(\mathrm{c}_{6} \mathrm{c}_{8} \mathrm{c}_{9}-\mathrm{c}_{6} \mathrm{~s}_{8} \mathrm{~s}_{9} \mathrm{P}_{1}\right)
$$

\section{Function Generation Synthesis}

Let the function to be generated be $\mathrm{z}=\mathrm{f}(\mathrm{x}, \mathrm{y})$ for $\mathrm{x}_{\min } \leq \mathrm{x} \leq \mathrm{x}_{\max }$ and $\mathrm{y}_{\min } \leq \mathrm{y} \leq$ $\mathrm{y}_{\max }$. The independent variables $\mathrm{x}$ and $\mathrm{y}$ should be related to the mechanism inputs $\theta$ and $\phi$ and the dependent variable $\mathrm{z}$ should be related to the mechanism output $\eta$. Via method of decomposition the intermediate joint angle $\psi$ should be related to an intermediate variable $\mathrm{w}$ such that $\mathrm{w}=\mathrm{g}(\mathrm{x}, \mathrm{y})$ and $\mathrm{z}=\mathrm{h}(\mathrm{w})=\mathrm{f}(\mathrm{x}, \mathrm{y}) . \theta, \phi, \psi$ and $\eta$ can be chosen in arbitrary ranges $\theta_{\min } \leq \theta \leq \theta_{\max }, \phi_{\min } \leq \phi \leq \phi_{\max }, \psi_{\min } \leq \psi \leq$ $\psi_{\max }, \eta_{\min } \leq \psi \leq \eta_{\max }$. We shall linearly relate $\mathrm{x}, \mathrm{y}, \mathrm{w}$ and $\mathrm{z}$ to $\theta, \phi, \psi$ and $\eta$ as

$$
\begin{gathered}
\frac{\mathrm{x}-\mathrm{x}_{\min }}{\mathrm{x}_{\max }-\mathrm{x}_{\min }}=\frac{\theta-\theta_{\min }}{\theta_{\text {max }}-\theta_{\min }}, \frac{\mathrm{y}-\mathrm{y}_{\min }}{\mathrm{y}_{\max }-\mathrm{y}_{\min }}=\frac{\phi-\phi_{\min }}{\phi_{\max }-\phi_{\min }}, \\
\frac{\mathrm{w}-\mathrm{w}_{\min }}{\mathrm{w}_{\text {max }}-\mathrm{w}_{\min }}=\frac{\psi-\psi_{\min }}{\psi_{\max }-\psi_{\min }} \text { and } \frac{\mathrm{z}-\mathrm{z}_{\min }}{\mathrm{z}_{\max }-\mathrm{z}_{\min }}=\frac{\eta-\eta_{\min }}{\eta_{\max }-\eta_{\min }}
\end{gathered}
$$

Then desired $\psi$ and $\eta$ values for given inputs $\theta$ and $\phi$ are found as follows:

$$
\begin{aligned}
& \theta=\frac{\theta_{\text {max }}-\theta_{\text {min }}}{\mathrm{x}_{\text {max }}-\mathrm{x}_{\text {min }}}\left(\mathrm{x}-\mathrm{x}_{\min }\right)+\theta_{\text {min }}, \phi=\frac{\phi_{\max }-\phi_{\min }}{\mathrm{y}_{\text {max }}-\mathrm{y}_{\text {min }}}\left(\mathrm{y}-\mathrm{y}_{\text {min }}\right)+\phi_{\min }, \\
& \psi=\frac{\psi_{\max }-\psi_{\min }}{\mathrm{w}_{\text {max }}-\mathrm{w}_{\text {min }}}\left(\mathrm{g}(\mathrm{x}, \mathrm{y})-\mathrm{w}_{\min }\right) \text { and } \eta=\frac{\eta_{\max }-\eta_{\min }}{\mathrm{z}_{\text {max }}-\mathrm{z}_{\min }}\left(\mathrm{f}(\mathrm{x})-\mathrm{z}_{\min }\right)+\eta_{\text {min }}
\end{aligned}
$$

and conversely 


$$
\begin{aligned}
& \mathrm{x}=\frac{\theta-\theta_{\text {min }}}{\theta_{\text {max }}-\theta_{\text {min }}}\left(\mathrm{x}_{\text {max }}-\mathrm{x}_{\text {min }}\right)+\mathrm{x}_{\min }, \mathrm{y}=\frac{\phi-\phi_{\min }}{\phi_{\max }-\phi_{\min }}\left(\mathrm{y}_{\max }-\mathrm{y}_{\min }\right)+\mathrm{y}_{\min }, \\
& \mathrm{w}=\frac{\psi-\psi_{\min }}{\psi_{\max }-\psi_{\min }}\left(\mathrm{w}_{\max }-\mathrm{w}_{\text {min }}\right)+\mathrm{w}_{\min } \text { and } \mathrm{z}=\frac{\eta-\eta_{\min }}{\eta_{\max }-\eta_{\min }}\left(\mathrm{z}_{\max }-\mathrm{z}_{\min }\right)+\mathrm{z}_{\text {min }}
\end{aligned}
$$

Eq. (13) is used for determining the design points $\theta_{i}, \phi_{i}, \psi_{i}$ and $\eta_{i}$ from $x_{i}, y_{i}$, $\mathrm{w}_{\mathrm{i}}=\mathrm{g}\left(\mathrm{x}_{\mathrm{i}}, \mathrm{y}_{\mathrm{i}}\right)$ and $\mathrm{z}_{\mathrm{i}}=\mathrm{f}\left(\mathrm{x}_{\mathrm{i}}, \mathrm{y}_{\mathrm{i}}\right)$. Selection of $\mathrm{x}_{\mathrm{i}}$ and $\mathrm{y}_{\mathrm{i}}$ may be done with equal spacing, Chebyshev spacing, or any other type of spacing.

In least squares approximation the number of design points, $n$, should be more than the number of construction parameters $m(=5$ for the 5 -bar and 4 for the 4 bar mechanism) and the aim is to minimize the square sum of the errors at the design points $\mathbf{x}_{\mathrm{i}}$ for $\mathrm{i}=1, \ldots, \mathrm{n}$. Due to the generation error, Eq. (5) is not exactly satisfied, but there is an error $\delta_{\mathrm{i}}$. In order to find the minimum of the square sum we differentiate the square sum with respect to coefficients $P_{j}$ and equate to zero:

$$
\frac{d}{d P_{j}}\left\{\sum_{i=1}^{n}\left[\sum_{j=1}^{m} P_{j} f_{j}\left(\mathbf{x}_{i}\right)-F\left(\mathbf{x}_{i}\right)\right]^{2}\right\}=0 \text { for } j=1, \ldots, m
$$

Eqs. (15) are linear in $\mathrm{P}_{\mathrm{j}}$, hence $\mathrm{P}_{\mathrm{j}}$ can be determined uniquely. However there are some restrictions on $\mathrm{P}_{\mathrm{j}}$ in order to obtain a mechanism. For instance, from Eq. (7) we see that $\left|P_{5}\right| \leq\left|P_{4}\right|$ in order to be able to compute $\cos ^{-1}$.

The maximum percentage error is defined as

$$
\%|\mathrm{E}|_{\max }=\max \left(\left|\frac{\mathrm{z}_{\text {desired }}-\mathrm{z}_{\text {generated }}}{\mathrm{z}_{\text {desired }}}\right| \times 100\right)
$$

During the computations $\%|\mathrm{E}|_{\max }$ is monitored and the freely chosen parameters that are associated with selection of the intermediate function $\mathrm{w}$ and the limits of the input/output joint variables are tuned in order to minimize the maximum error.

\section{Case Study}

As an example consider the function $\mathrm{z}=\mathrm{x}^{0.6} \mathrm{y}^{0.2}$ for $5 \leq \mathrm{x} \leq 10$ and $14 \leq \mathrm{y} \leq 17$. We defined the intermediate variable as $\mathrm{w}=\mathrm{x}^{\mathrm{a}} \mathrm{y}^{\mathrm{b}}$ such that $\mathrm{z}=\mathrm{w}^{\mathrm{c}}$, where can be chosen freely, $\mathrm{a}=0.6 / \mathrm{c}$ and $\mathrm{b}=0.2 / \mathrm{c}$. We employed 25 design points as equally spaced 5 by 5 grid for the inputs $\mathrm{x}$ and $\mathrm{y}$. The limits of the inputs $\theta$ and $\phi$, the passive joint variable $\psi$ and the output $\eta$ of the mechanism are also free to choose. Therefore, there are 9 free parameters in this synthesis problem. After several trials on the free parameters, a solution with relatively low error is determined for 
$\mathrm{c}=0.9,145^{\circ} \leq \theta \leq 300^{\circ}, 100^{\circ} \geq \phi \geq 80^{\circ}, 105^{\circ} \leq \psi \leq 185^{\circ}$ and $250^{\circ} \geq \eta \geq 185^{\circ}$. The maximum percentage error is found as $0.656 \%$. The maximum percentage error can be further decreased; however the link length ratios get worse. Percentage error variation is depicted in Fig. 2. For comparison we also worked out the synthesis with a spherical $5 \mathrm{R}$ mechanism for the same function and maximum percentage error is found as $0.834 \%$.

The construction parameters of the designed 7R mechanism are $\alpha_{1}=126.13^{\circ}$, $\alpha_{2}=31.61^{\circ}, \alpha_{3}=127.69^{\circ}, \alpha_{4}=17.89^{\circ}, \alpha_{5}=86.65^{\circ}, \alpha_{6}=28.47^{\circ}, \alpha_{7}=171.52^{\circ}$, $\alpha_{8}=35.52^{\circ}$ and $\alpha_{9}=166.74^{\circ}$. It is verified that the mechanism successfully generates the desired function by means of a CAD model which is given in Fig. 3 .

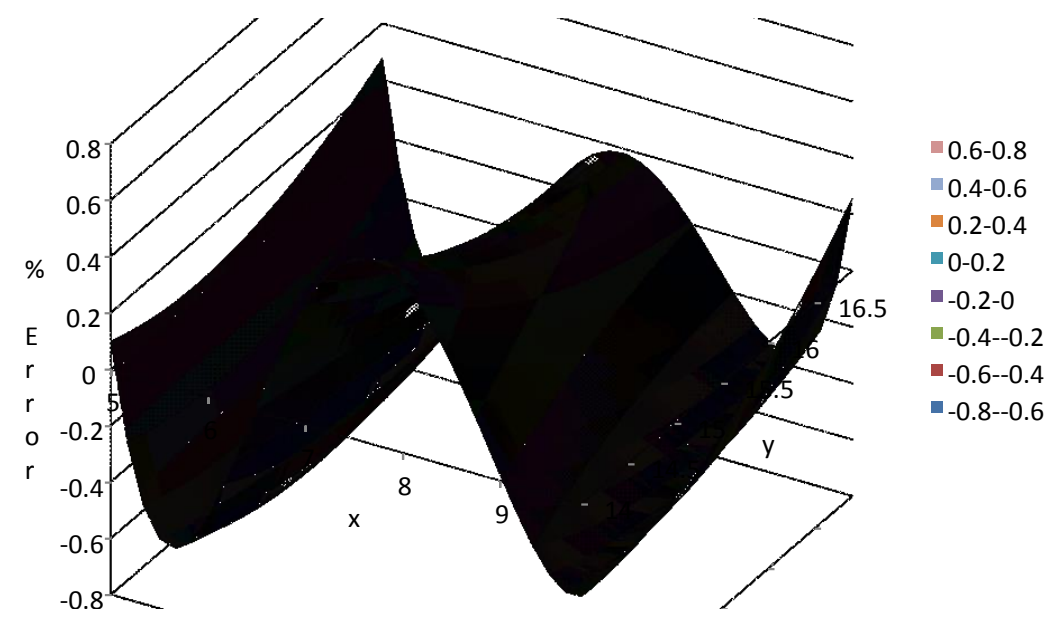

Fig. 2 Percentage error variation for generation of $z=x^{0.6} y^{0.2}$

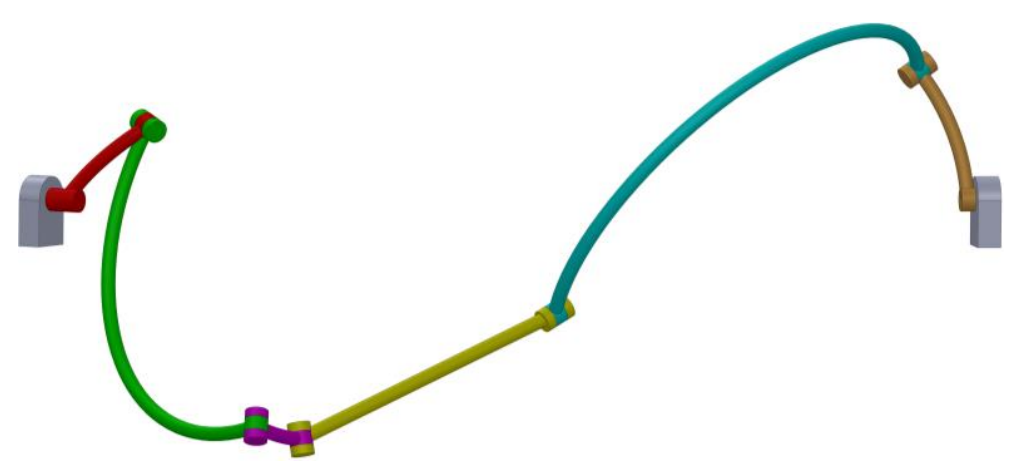

Fig. 3 CAD model of the designed 7R mechanism 


\section{Conclusions}

This study focuses on formulation of function generation synthesis of an overconstrained 2-dof 7R mechanism using least squares approximation and making use of method of decomposition. The inputs of the mechanism are chosen such that the resulting synthesis equations are linear. Several case studies are performed and one of them is presented. The case study shows that the maximum error may be decreased by use of a $7 \mathrm{R}$ mechanism instead of a spherical $5 \mathrm{R}$ mechanism. Future studies involve applying other approximation methods for the $7 \mathrm{R}$ mechanism and comparing the results.

Acknowledgments The authors thank Prof. Rasim Alizade for his guidance

\section{References}

14. Alizade, R. I., Aydazade, K. P. and Novruzbekov, I. G.: Analysis and synthesis of planar mechanisms by using decomposition method. J. Mechanics of Machines, The Academy of Sciences of the USSR, 57, 26-32 (1980)

10. Alizade, R. I., Kiper, G., Dede, M. İ. C. and Uzunoğlu, E.: Derivation of input-output relationship for the Bennett 6R linkages based on the method of decomposition. In: New Advances in Mechanisms, Transmissions and Applications - Proceedings of the Second Conference MeTrApp (Series: Mechanisms and Machine Science). Springer (2013)

11. Alizade, R. I., Kiper, G., Bağdadioğlu, B. and Dede, M. İ. C.: Function synthesis of Bennett 6R mechanisms using Chebyshev approximation. To appear in Mech. Mach. Theory (2014)

5. Alizade, R. I., Rao, A. V. M. and Sandor, G. N.: Optimum synthesis of two-degree-offreedom planar and spatial function generating mechanisms using the penalty function approach. J. Eng. Ind., 97, 629-634 (1975)

13. Alizade, R. I., Selvi, Ö. and Gezgin, E.: Structural synthesis of parallel manipulators with general constraint one. Mech. Mach. Theory, 45, 1-14 (2010)

12. Bennett, G. T.: The parallel motion of Sarrus and some allied mechanisms. Philos. Mag., $6^{\text {th }}$ series, 9, 803-810 (1905)

1. Huang, Z., Li, Q. and Ding, H.: Theory of Parallel Mechanisms (Series: Mechanisms and Machine Science). Springer (2013)

7. Kiper, G., Bilgincan, T. and Dede, M.I.C.: Function generation synthesis of planar 5R mechanism. Prob. Mech., 51, 28-31 (2013)

8. Kiper, G., Bağdadioğlu, B. and Bilgincan, T.: Function synthesis of the planar 5R mechanism using least square approximation. Accepted for presentation in the $14^{\text {th }}$ International Symposium on Advances in Robot Kinematics (2014a)

9. Kiper, G. and Bilgincan, T.: Function generation synthesis of spherical 5R mechanism. To appear in Mech. Mach. Theory (2014b)

6. Kim, Tsai: Kinematic synthesis of a spatial 3-RPS parallel manipulator. J. Mech. Des., 125, 92-97 (2003)

4. McCarthy, J. M. and Soh, G. S.: Geometric Design of Linkages, $2^{\text {nd }}$ Ed., Springer (2011)

3. Sandor, G. N. and Erdman, A. G.: Advanced Mechanism Design: Analysis and Synthesis, Vol. 2, Prentice Hall (1984)

2. Vaida, C. et al..: Structural analysis and synthesis of parallel robots for brachytherapy. In: New Trends in Medical and Service Robots. Springer (2014) 